\title{
OCORRÊNCIA DE COMMELINA VILLOSA COMO PLANTA DANINHA EM ÁREAS AGRÍCOLAS NO ESTADO DO PARANÁ-PR, BRASIL ${ }^{1}$
}

\author{
DALVA C. ROCHA ${ }^{2}$, ROBERTO A. RODELLA ${ }^{3}$ e DAGOBERTO MARTINS ${ }^{4}$
}

\section{RESUMO}

As trapoerabas pertencem à família Commelinaceae e são plantas daninhas de difícil controle em diferentes regiões do país. No Brasil, a espécie Commelina benghalensis destaca-se como a principal trapoeraba infestante nas culturas de soja, milho, café e citros. Outras duas espécies desse gênero, Commelina diffusa e Commelina erecta, também são conhecidas como infestantes de ocorrência freqüente no território nacional. Commelina villosa está registrada, até o momento, apenas para os Estados da Bahia e Goiás além do Distrito Federal. O presente trabalho teve como objetivos caracterizar e registrar a ocorrência de C. villosa no Estado do Paraná, onde pode estar sendo confundida com outras trapoerabas, principalmente $C$. benghalensis. Exemplares de C. villosa e $C$. benghalensis foram coletados, de forma aleatória, em lavouras de soja, feijão e milho, nos municípios de Ponta Grossa, Tibagi, Piraí do
Sul, Guarapuava, Pato Branco, Francisco Beltrão, Cascavel, Campo Mourão e Londrina. Parte desse material foi herborizado para a confecção de exsicatas e outra parte foi mantida in vivo, cultivada no Departamento de Botânica, do Instituto de Biociências de Botucatu-UNESP. Caracteres morfológicos descritivos e quantitativos foram avaliados e as espécies comparadas entre si. C. villosa distinguiu-se de $C$. benghalensis por apresentar folhas maiores $(9,76 \times 3,26 \mathrm{~cm})$, elíptica a elípticaestreita, sésseis, de coloração verde escura com manchas violáceas na face inferior, filetes translúcidos, entre outras características. A ocorrência de C. villosa no Paraná foi constatada em todos os municípios amostrados, com exceção de Campo Mourão e Londrina.

Palavras chave: Trapoerabas, Commelinaceae, Commelina benghalensis.

\section{ABSTRACT}

\section{Occurence of Commelina villosa as weed in Paraná State, Brazil}

Commelinaceae are weeds with unsatisfactory control in different parts of the country. Commelina benghalensis is the main Commelinaceae weed in soybean, corn, coffee and orange crops in Brazil. Commelina diffusa and Commelina erecta are also known as common weeds in national territory. Commelina villosa is only related, until this moment, to Bahia and Goiás States and to Distrito Federal, too. The present paper intented to identify and to relate
C. villosa as weed in Paraná State crops, where it may have been confused with other Commelina species, mainly C. benghalensis. Samples of $C$. villosa and C. benghalensis were collected, in Ponta Grossa, Tibagi, Piraí do Sul, Guarapuava, Pato Branco, Francisco Beltrão, Cascavel, Campo Mourão and Londrina cities, from soybean, bean and corn crops. One part of these material was used to make exsicates and the other one was

\footnotetext{
${ }^{1}$ Recebido para publicação em 05/07/98 e na forma revisada em 11/10/98.

${ }^{2}$ Prof $^{\text {a }}$ Assistente, Dept ${ }^{\circ}$ de Biologia/Universidade Estadual de Ponta Grossa/PR, CEP: 84030-000.

${ }^{3}$ Prof $^{\circ}$ Assistente Dr, Instituto de Biociências/UNESP, Botucatu/SP, CEP: 18618-000.

${ }^{4}$ Prof $^{\circ}$ Assistente Dr, Faculdade de Ciências Agronômicas/UNESP, Botucatu/SP, CEP: 18603-970.
} 
cultivated at Departamento de Botânica of Instituto de Biociências de Botucatu-UNESP. Morphological characters were analysed and these species were confronted. Analysis of variance were used for quantitatives datas. C. villosa was distinguished because it has translucent fillets, bigger $(9.76 \times 3.26 \mathrm{~cm})$ eliptical or eliptical-narrow leaves without petiole which are dark green with violet spots in the under surface, among others characteristics. The occurrence of C. villosa in Paraná State was related in all that cities unless Campo Mourão and Londrina.

Key words: Spideflower, Commelinaceae, Commelina benghalensis.

\section{INTRODUÇÃO}

As trapoerabas (Commelinaceae) são plantas daninhas de difícil controle em algumas regiões do país (Carvalho et al., 1991; Galli, 1991; Ramos \& Durigan, 1996). Essa dificuldade pode estar relacionada ao reconhecimento das espécies ocorrentes na lavoura (Rocha, 1999).

Principalmente, em lavouras de soja, essas plantas podem causar grandes prejuízos (Gazziero, 1985). Commelina benghalensis L. é a trapoeraba mais frequente e somente outras duas espécies desse gênero, Commelina diffusa Burm. f. e Commelina erecta L., são citadas como plantas daninhas de ocorrência no território nacional (Kissmann, 1997).

Commelina villosa C. B. Clarke ex Chod. \& Hassl. está registrada, no Brasil, apenas para o Distrito Federal e para os Estados de Goiás e da Bahia. Essa espécie também é conhecida pelos binômios Commelina monticola Seub. e Commelina vestida Seub., ambos descritos em 1855 com base nos materiais coletados, respectivamente, em Minas Gerais e no Brasil Meridional (Barreto, 1997).

A espécie $C$. benghalensis tem como característica peculiar a presença de botões florais subterrâneos, o que facilita o seu reconhecimento no campo. No entanto, a identificação das outras espécies não se faz com facilidade, sem antes analisar, principalmente, as peças florais (Barreto, 1997; Kissmann, 1997).

O presente trabalho teve como objetivos caracterizar e registrar a ocorrência de C. villosa em áreas agrícolas no Estado do Paraná.

\section{MATERIAL E MÉTODOS}

Exemplares de Commelina villosa e Commelina benghalensis foram amostrados, de forma aleatória, em nove cidades (Ponta Grossa, Tibagi, Piraí do Sul, Guarapuava, Pato Branco, Francisco Beltrão, Cascavel, Campo Mourão e Londrina) do Estado do Paraná.

Parte do material coletado foi herborizado e as exsicatas depositadas no Herbário BOTU, da UNESP, em Botucatu-SP. Outra parte do material foi cultivada no Departamento de Botânica, do Instituto de Biociências de Botucatu-UNESP.

A partir da análise do material in vivo, selecionaram-se 24 caracteres morfológicos vegetativos e florais de diferenciação, entre as duas espécies, sendo 10 caracteres morfológicos descritivos e 14 quantitativos.

Os caracteres morfológicos descritivos analisados foram: hábito da planta; cor da base do caule, da lâmina foliar, das nervuras da bainha, dos filetes e do pólen dos estames laterais; forma da lâmina foliar e da antera do estame central; presença de mancha violácea na lâmina foliar; tipo de folha. Os dados referentes às cores foram obtidos por comparações com a Carta de Cores da Enciclopédia Exótica (Graf, 1970) e a classificação do formato da lâmina foliar foi baseada em Hickey (1979).

Os parâmetros morfológicos quantitativos mensurados foram: comprimento e largura da terceira folha (contada do ápice para a base), da espata, das pétalas e das sépalas; comprimento do maior pedúnculo, do estame central, do estame lateral e do estaminódio; número de inflorescências por espata e de flores por inflorescência. Os valores médios foram obtidos a partir de dez repetições e, posteriormente, os dados foram submetidos à análise estatística (Pimentel-Gomes, 1976). 


\section{RESULTADOS E DISCUSSÃO}

A espécie de trapoeraba mais freqüentemente citada como infestante em lavouras do Paraná é C. benghalensis (Lorenzi, 2000). A presença de botões florais no sistema subterrâneo é um caracter importante para a sua identificação (Barreto, 1997; Kissmann, 1997).

As outras espécies de Commelina são muito semelhantes, quando observadas na fase vegetativa, sendo possível confundi-las entre si. Foram encontradas duas populações de trapoerabas, infestando uma mesma lavoura de feijão no município de Tibagi, sendo possível identificar uma delas como $C$. benghalensis, devido à presença de botões florais no sistema subterrâneo. A outra população foi identificada como C. villosa, mediante a análise dos caracteres morfológicos vegetativos e florais.

C. villosa não consta como espécie de Commelinaceae infestante (Kissmann, 1997) e, até o momento, sua ocorrência não havia sido registrada para o Estado do Paraná (Barreto, 1997). No entanto, Barreto (1997) menciona que Commelina vestida, atualmente sinonímia de $C$. villosa, foi coletada em meados do século XIX no Brasil Meridional e cita também, que antes de ter sido elevada ao nível de espécie, foi descrita como Commelina virginica $\mathrm{L}$. var. villosa C. B. Clarke para o Estado do Rio Grande do Sul.

As Tabelas 1 e 2 mostram, respectivamente, os caracteres morfológicos descritivos e morfológicos quantitativos, que permitem a diferenciação entre $C$. villosa e $C$. benghalensis.

C. villosa caracteriza-se por apresentar porte ereto, podendo alcançar até $1 \mathrm{~m}$ de altura, diferentemente de $C$. benghalensis que tem hábito decumbente (Figura 1 A). O caule apresenta coloração verde escura com porções violáceas, principalmente, na base. As folhas são também de coloração verde escura e com manchas violáceas na face inferior, apresentando $9,76 \mathrm{~cm}$ de comprimento e $3,26 \mathrm{~cm}$ de largura, caracterizandose por serem sésseis, elíptica a elíptica-estreita, de base oblíqua e bainha de coloração verde com nervuras violáceas.

Com relação às características florais, $C$. villosa apresenta espata com dimensões médias de $1,98 \mathrm{~cm}$ de comprimento e $1,46 \mathrm{~cm}$ de largura, protegendo duas ou três inflorescências, com pedúnculo apresentando $2,52 \mathrm{~cm}$ de comprimento. Essa espécie produz cerca de 9,20 flores por inflorescência, ou seja, o triplo de flores produzidas por C. benghalensis.

Quanto aos verticilos florais, C. villosa apresentou maiores dimensões de sépalas, pétalas, estames e estaminódios, quando comparados com C. benghalensis. Todos os filetes de C. villosa têm coloração translúcida, enquanto em $C$. benghalensis todos são roxos. A forma da antera do estame central é auricular para $C$. villosa e sagitada para $C$. benghalensis. A coloração amarela é uma das características do pólen de todos os estames de $C$. villosa, diferentemente de C. benghalensis (Figuras $1 \mathrm{~B}-\mathrm{C}$ ).

De maneira geral, C. villosa (Figura 2 A) pode ser diferenciada de $C$. benghalensis (Figura 2 B), principalmente, por apresentar as seguintes características: hábito ereto, folhas maiores e sésseis, maior comprimento de pedúnculo e espata, pétalas e sépalas maiores, maior comprimento e coloração translúcida dos filetes, forma auricular da antera do estame central e pólen amarelo em todos os estames.

C. villosa possivelmente apresenta alto potencial de infestação, devido à presença de grande área foliar, elevado número de inflorescências por espata e número de flores por inflorescência.

\section{AGRADECIMENTOS}

Aos Engenheiros Agrônomos Giovanni Scortegagña (FMC do Brasil Ltda.), José Roberto Vieira e Pedro Luís de Araújo e Campos (Agroplan, Guarapuava-PR) e ao Sr. Carlos Grochovski (Administrador da Fazenda Jangada, Tibagi-PR) pelo apoio técnico na realização das coletas. À Dra. Roxana Cardoso Barreto (Universidade Federal de Pernambuco) pela confirmação na identificação das espécies. 
TABELA 1. Caracteres morfológicos descritivos para diferenciação entre Commelina villosa e Commelina benghalensis.

\section{CARACTERÍSTICAS}

\section{Hábito da planta}

Cor da base do caule

Cor da lâmina foliar

Mancha violácea na lâmina foliar

Forma da lâmina foliar

Cor das nervuras da bainha

Tipo de folha

Forma da antera do estame central

Cor dos filetes

Cor do pólen dos estames laterais
C. villosa

ereto

violácea (54/violet)

verde escuro (70/ivy)

face inferior (48/indigo)

elíptica a elíptica-estreita

violácea (42/maroon)

$$
\text { séssil }
$$

auricular

translúcido

\section{C. benghalensis}

decumbente

verde (83/fern green)

verde claro (81/lettuce)

ausente

elíptica a elíptica ovada

verde (80/nile green)

peciolada

sagitada

roxo (48/indigo)

TABELA 2. Caracteres morfológicos quantitativos para diferenciação entre Commelina villosa e Commelina benghalensis.

\begin{tabular}{lcccc}
\hline \multicolumn{1}{c}{ CARACTERíSTICAS } & C. villosa & C. benghalensis & CV (\%) \\
\hline Comprimento (cm) da terceira folha & $9,76 \mathrm{a}$ & $4,17 \mathrm{~b}$ & 22,94 \\
Largura (cm) da terceira folha & $3,26 \mathrm{a}$ & $1,92 \mathrm{~b}$ & 13,66 \\
Número de inflorescências / espata & $2,50 \mathrm{a}$ & $2,00 \mathrm{~b}$ & 4,30 \\
Número de flores / inflorescência & $9,20 \mathrm{a}$ & $3,10 \mathrm{~b}$ & 5,10 \\
Comprimento (cm) do maior pedúnculo & $2,52 \mathrm{a}$ & $1,85 \mathrm{~b}$ & 10,06 \\
Comprimento (cm) da espata & $1,98 \mathrm{a}$ & $1,10 \mathrm{~b}$ & 10,81 \\
Largura (cm) da espata & $1,46 \mathrm{a}$ & $0,85 \mathrm{~b}$ & 5,50 \\
Comprimento (cm) das pétalas & $0,70 \mathrm{a}$ & $0,47 \mathrm{~b}$ & 12,86 \\
Largura (cm) das pétalas & $0,89 \mathrm{a}$ & $0,60 \mathrm{~b}$ & 10,41 \\
Comprimento (cm) das sépalas & $0,49 \mathrm{a}$ & $0,30 \mathrm{~b}$ & 10,79 \\
Largura (cm) das sépalas & $0,35 \mathrm{a}$ & $0,21 \mathrm{~b}$ & 14,79 \\
Comprimento (cm) do estame central & $0,64 \mathrm{a}$ & $0,42 \mathrm{~b}$ & 8,19 \\
Comprimento (cm) do estame lateral & $0,92 \mathrm{a}$ & $0,57 \mathrm{~b}$ & 6,28 \\
Comprimento (cm) do estaminódio & $0,47 \mathrm{a}$ & $0,30 \mathrm{~b}$ & 14,88 \\
\hline
\end{tabular}

Médias seguidas de letras desiguais na linha diferem estatisticamente entre si $(\mathrm{P}<0,01)$. 

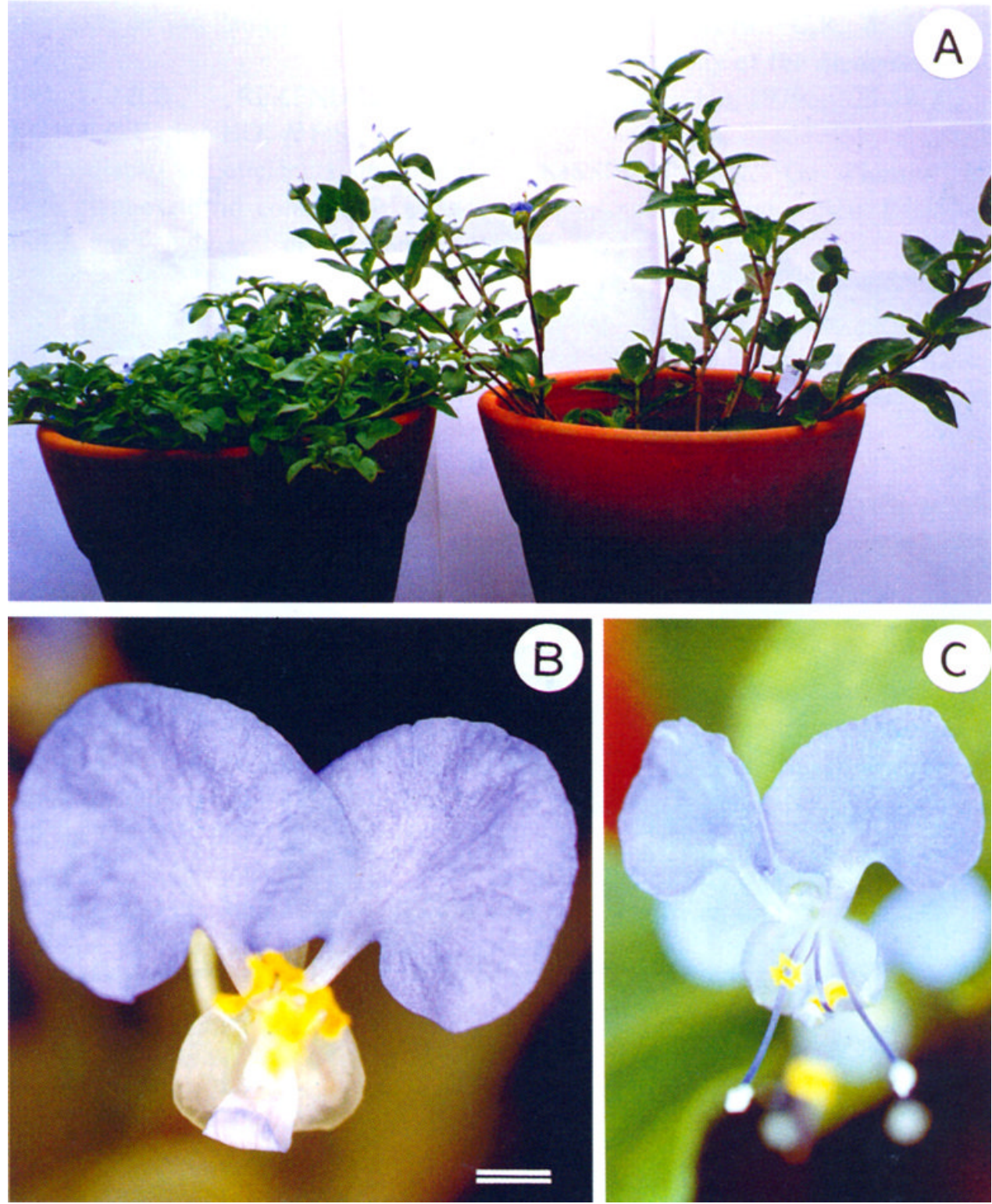

FIGURA 1. A: Hábito das plantas de Commelina benghalensis (esquerda) e Commelina villosa (direita). B: Estrutura da flor de Commelina villosa. C: Estrutura da flor de Commelina benghalensis. Barra $=2 \mathrm{~mm}(\mathbf{B}-\mathbf{C})$. 


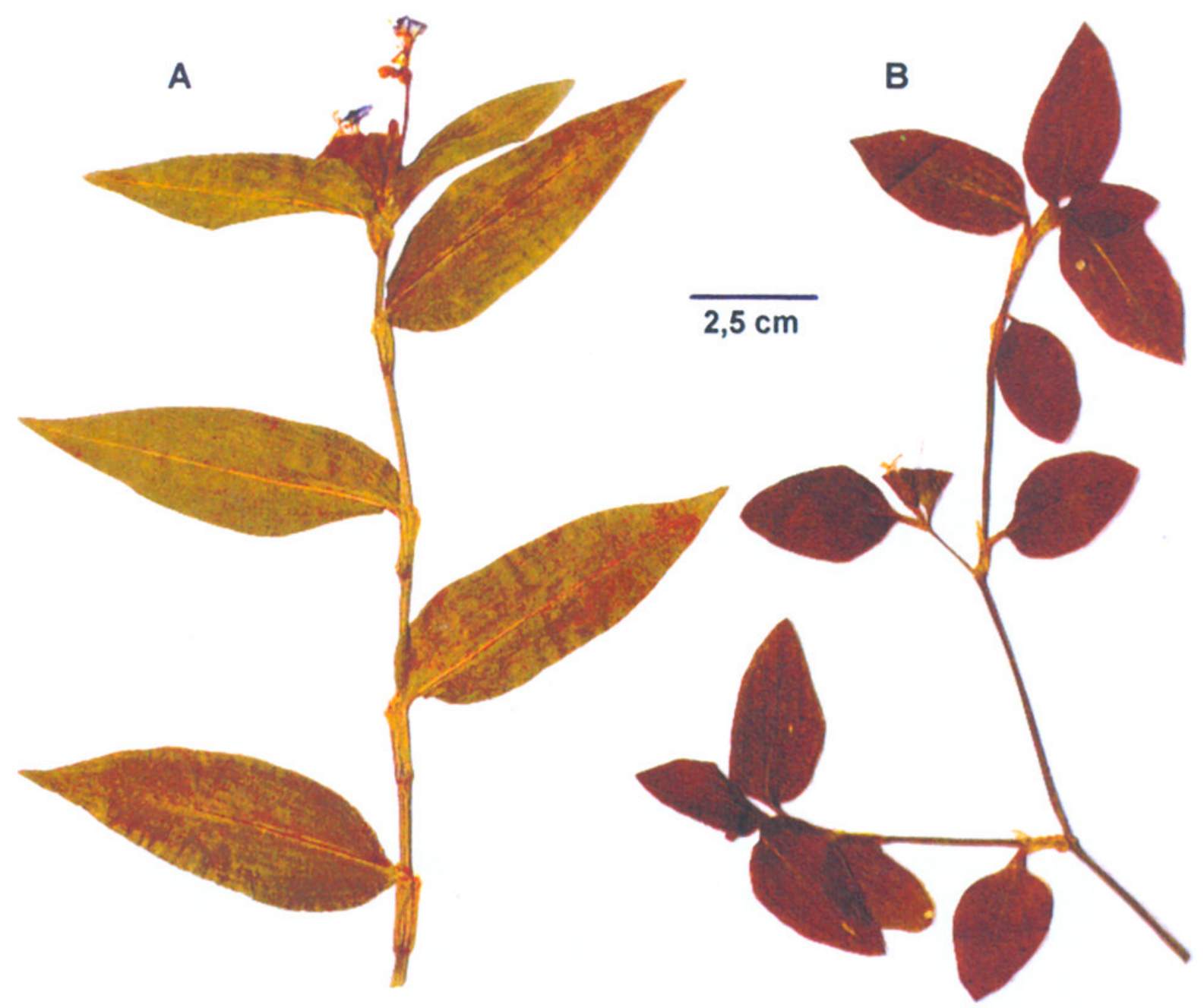

FIGURA 2. Aspecto das plantas herborizadas. A: Commelina villosa. B: Commelina benghalensis. 


\section{LITERATURA CITADA}

BARRETO, R.C. Levantamento das espécies de Commelinaceae R. Br. nativas do Brasil. São Paulo, USP, 1997. 490p. (Tese de Doutorado, Instituto de Biociências da Universidade de São Paulo).

CARVALHO, J.E.B., REZENDE, G.O., PEIXOTO, C.P., PINHO, A.F.S., FOLONI, L.L. Avaliação da eficiência do produto 2,4-D + glyphosate no controle de plantas daninhas na cultura de cacau. In: CONGRESSO BRASILEIRO DE HERBICIDAS E PLANTAS DANINHAS, 18, 1991. Resumos... Brasília: SBHED, 1991. p. 95-96.

GALLI, A.J.B. Avaliação da eficiência de glyphosate em diversos produtos no controle de Commelina virginica (trapoeraba) em citros. In: CONGRESSO BRASILEIRO DE HERBICIDAS E PLANTAS DANINHAS, 18, 1991. Resumos... Brasília: SBHED, 1991. p. 104-105.

GAZZIERO, D.L.P. O controle de plantas daninhas na cultura da soja. Inf. Plantio Direto, n.13, p. 2-3, 1985.

GRAF, A.B. Exotica Horticultural Color Guide.
In: GRAF, A.B. Exotica 3: Pictorial encyclopedia of exotic plants. Rutherford, Roehrs, 1970. p. 37-38.

HICKEY, L.J. A revised classification of the architecture of dicotyledonous leaves. In: METCALFE, C.R. \& CHALKE, L., ed. Anatomy of the dicotyledons. 2ed. Oxford, Clarendon, 1979. p. 25-39.

KISSMANN, K. G. Plantas infestantes e nocivas. 2ed. São Paulo, BASF, 1997. 824p.

LORENZI, H. Plantas daninhas do Brasil: terrestres, aquáticas, parasitas e tóxicas. 3ed. Nova Odessa, Instituto Plantarum, 2000. 608 p.

PIMENTEL-GOMES, F. Curso de estatística experimental. 6ed. Piracicaba, Binetti, 1976. 430p

RAMOS, H.H. \& DURIGAN, J.C. Avaliação da eficiência da mistura pronta de glyphosate + 2,4-D no controle de Commelina virginica L. em citros. Planta Daninha, v. 14, n.1, p. 33-41, 1996.

ROCHA, D.C. Belas, invasoras e tolerantes. Cultivar, v.11, p. 24-25, 1999. 